\title{
Pembelajaran Berbasis Riset sebagai Upaya Peningkatan Minat Belajar Siswa terhadap Materi Perubahan Fisika Kimia
}

\author{
Erna Widyasari \\ SMP Al Azhar Syifa Budi Solo \\ Email: supmatahari@yahoo.com
}

\begin{abstract}
Abstrak
Pada revolusi industri 4.0, inovasi merupakan target utama. Prinsip pembelajaran berubah menjadi learning by doing atau experiential learning. Dalam melakukan inovasi pendidikan, kita bisa mempertimbangkan pembelajaran berbasis riset. Inovasi yang dilakukan diharapkan dapat menjadi pembelajaran yang bermanfaat. Pembelajaran berbasis riset akan melatih daya nalar, daya mencipta, dan berpikir kritis siswa sehingga melahirkan generasi yang berbudaya ilmiah dan pemberi solusi atas masalah yang ada pada lingkungan sekitar. Materi perubahan fisika kimia umumnya hanya diberikan oleh guru melalui metode pencarian literatur maupun pemberian contoh-contoh perubahan yang terjadi dalam bentuk gambar atau benda yang konkret. Dengan metode pembelajaran berbasis riset, siswa akan lebih tertarik dan aktif dalam belajar, terlebih jika riset tersebut dapat menanggulangi permasalahan yang ada di sekitar mereka. Pembuatan cokelat dilakukan sebagai contoh dari perubahan fisika yang dapat kembali ke bentuk semula. Pembuatan bioplastik sebagai contoh dari perubahan kimia yang menghasilkan zat yang jenisnya baru dan tidak dapat kembali ke bentuk semula. Dari pembelajaran riset yang telah dilakukan oleh siswa, dilakukan evaluasi efektivitas pembelajaran melalui pengisian lembar evaluasi. Hasil evaluasi yang dilakukan pada 26 siswa menunjukkan 25 siswa memahami materi perubahan fisika kimia dengan baik dan 1 siswa belum memahami materi.
\end{abstract}

Kata kunci: Pembelajaran Berbasis Riset, Minat Belajar, Perubahan Fisika Kimia

\section{Research-Based Learning as Effort to Increase Student Learning Interest towards Physical Chemical Changes Of Matter}

\begin{abstract}
On the industrial revolution 4.0, innovation is a prime target. Principles of learning, learning by doing is transformed into or experiential learning. In innovating education, we can consider the research-based learning. Innovation done expected can be a useful learning. Research-based learning, will exercise the power of reason, rationality, and the power of critical thinking students thus giving birth to the next generation of scientific and cultural solutions to problems that exist in the surrounding environment. Material changes in chemical physics is generally only given by teachers through a literature search methods as well as awarding examples of changes that occur in the form of pictures or concrete objects. Research-based learning methods, students will be more interested and active in learning, especially if the research can overcome problems that exist around them. Chocolate making is done as an example of a physical change can return to its original shape. Manufacturing of bioplastic as examples of chemical changes that result in new types of substances and can not return to its original shape. Learning from research that has been done by the students, carried out an evaluation of the effectiveness of learning via the charging sheet evaluation. The results of the evaluation conducted on 26 students show 25 students understand material changes in chemical physics and 1 students have yet to understand the material.
\end{abstract}

Keywords: Research-based Learning, Students Interest, Physical Chemical Changes of Matter 


\section{PENDAHULUAN}

Perubahan terus ada seiring dengan perkembangan zaman. Pembelajaran harus menyesuaikan perubahan tersebut, berubah menjadi learning by doing atau experiential learning. Dalam pembelajaran guru bisa mempertimbangkan pembelajaran berbasis riset. Inovasi yang dilakukan diharapkan dapat menjadi pembelajaran yang bermanfaat. Siswa akan aktif melakukan pembelajaran secara mandiri sehingga mampu meningkatkan pemahaman mereka tentang materi yang diajarkan. Apabila pembelajaran tersebut mampu menumbuhkan kreativitas, jiwa kewirausahaan, daya mencipta, serta kepedulian terhadap sesama dan lingkungan sekitar akan menambah nilai lebih untuk pembelajaran tersebut. Materi perubahan fisika kimia umumnya hanya diberikan oleh guru melalui metode pencarian literatur maupun pemberian contoh-contoh perubahan yang terjadi dalam bentuk gambar atau benda yang konkret. Dengan metode pembelajaran berbasis riset, siswa akan lebih tertarik dan aktif dalam belajar, terlebih jika riset tersebut dapat menanggulangi permasalahan yang ada di sekitar mereka. Pembuatan cokelat dilakukan sebagai contoh dari perubahan fisika yang dapat kembali ke bentuk semula. Pembuatan bioplastik sebagai contoh dari perubahan kimia yang menghasilkan zat yang jenisnya baru dan tidak dapat kembali ke bentuk semula. Dari pembelajaran riset yang telah dilakukan oleh siswa, dilakukan evaluasi efektivitas pembelajaran melalui pengisian lembar evaluasi.

Industri 4.0 sebagai fase revolusi teknologi mengubah cara beraktifitas manusia dalam skala, ruang lingkup, transformasi dari pengalaman hidup sebelumnya. Manusia bahkan akan hidup dalam ketidakpastian, oleh karena itu manusia harus memiliki kemampuan untuk memprediksi masa depan yang berubah sangat cepat. Pembelajaran yang baik dapat mengatasi permasalahan tersebut di masa yang akan datang (Yahya, 2018).

Perubahan dalam pembelajaran sesuai era 4.0 akan berdampak pada peran pendidikan khususnya peran pendidik. Kondisi tersebut harus diatasi dengan menambah kompetensi pendidik yang mendukung eksplorasi dan penciptaan melalui pembelajaran mandiri (Triyono, 2017). Perubahan kurikulum mengakibatkan perubahan pada metode pembelajaran. Kurikulum 2013 menekankan pada keterlibatan siswa untuk lebih aktif dalam proses pembelajaran. Pembelajaran aktif dan berpusat pada siswa bertujuan untuk mendorong keterampilan siswa (Istighfaroh, 2014).

Salah satu model pembelajaran yang mengajak siswa untuk berperan aktif selama proses pembelajaran dengan mengembangkan pengalaman-pengalaman siswa adalah experiential learning. Model experiential learning ini melibatkan siswa secara langsung dalam masalah dan isu yang dipelajari. Belajar menurut model experiential learning merupakan proses penciptaan 
pengetahuan melalui perpaduan antara mendapatkan pengalaman dan mentransformasi pengalaman (Nurhasanah, et al, 2017).

Experiential learning dibagi menjadi empat tahapan, yakni: tahapan pengalaman nyata, observasi, konseptualisasi, dan implementasi. Tahapan tersebut dimulai dengan percobaan, kemudian mengobservasinya. Dalam tahap observasi, siswa berusaha untuk memahami apa yang terjadi di dalamnya. Observasi ini menjadi dasar konseptualisasi atau proses pemahaman prinsip-prinsip yang mendasari pengalaman serta perkiraan kemungkinan aplikasinya dalam kehidupan sehari-hari (Aprilia, 2015).

\section{METODE}

Pembelajaran materi perubahan fisika kimia bersifat abstrak bagi siswa. Oleh karena itu, penulis membuat ide strategi pembelajaran yang berbasis riset. Selain menyenangkan, siswa dapat lebih memahami materi dengan melakukan dan melihat sendiri proses yang terjadi di dalamnya.

Kegiatan awal yang dilakukan adalah guru melakukan apersepsi dengan salam, berdoa, dan menanyakan kabar siswa, mengabsen dan menjelaskan tujuan dan langkah yang akan dilaksanakan. Kegiatan pembelajaran dilakukan selama 7 JP. Dua JP pertama digunakan untuk melaksanakan pembuatan cokelat, 2 JP selanjutnya untuk kegiatan pembuatan bioplastik, 2 JP selanjutnya untuk evaluasi pembelajaran dan pembuatan produk dari bioplastik, serta $1 \mathrm{JP}$ terakhir untuk tes tertulis.

Siswa yang melakukan evaluasi pembelajaran adalah kelas VII Imam Ibnu Majjah SMP Al Azhar Syifa Budi Solo Tahun Pelajaran 2018/2019 yang berjumlah 27 orang. Namun, dalam kegiatan evaluasi 1 siswa tidak masuk karena sakit sehingga siswa yang melaksanakan evaluasi hanya 26 siswa.

Kelas dibagi menjadi 5 kelompok, setiap kelompok membawa peralatan masing-masing yang diperlukan untuk pembuatan cokelat dan bioplastik. Siswa melaksanakan pembelajaran sesuai dengan arahan guru, terutama untuk komposisi bahan dasar pembuatan bioplastik.

Kegiatan terakhir adalah penutup. Guru dan siswa mengevaluasi dan menyimpulkan materi bersama-sama dan menutup pembelajaran. Pembelajaran dari awal sampai akhir dilakukan sesuai dengan prosedur dan rencana pelaksanaan pembelajaran. 


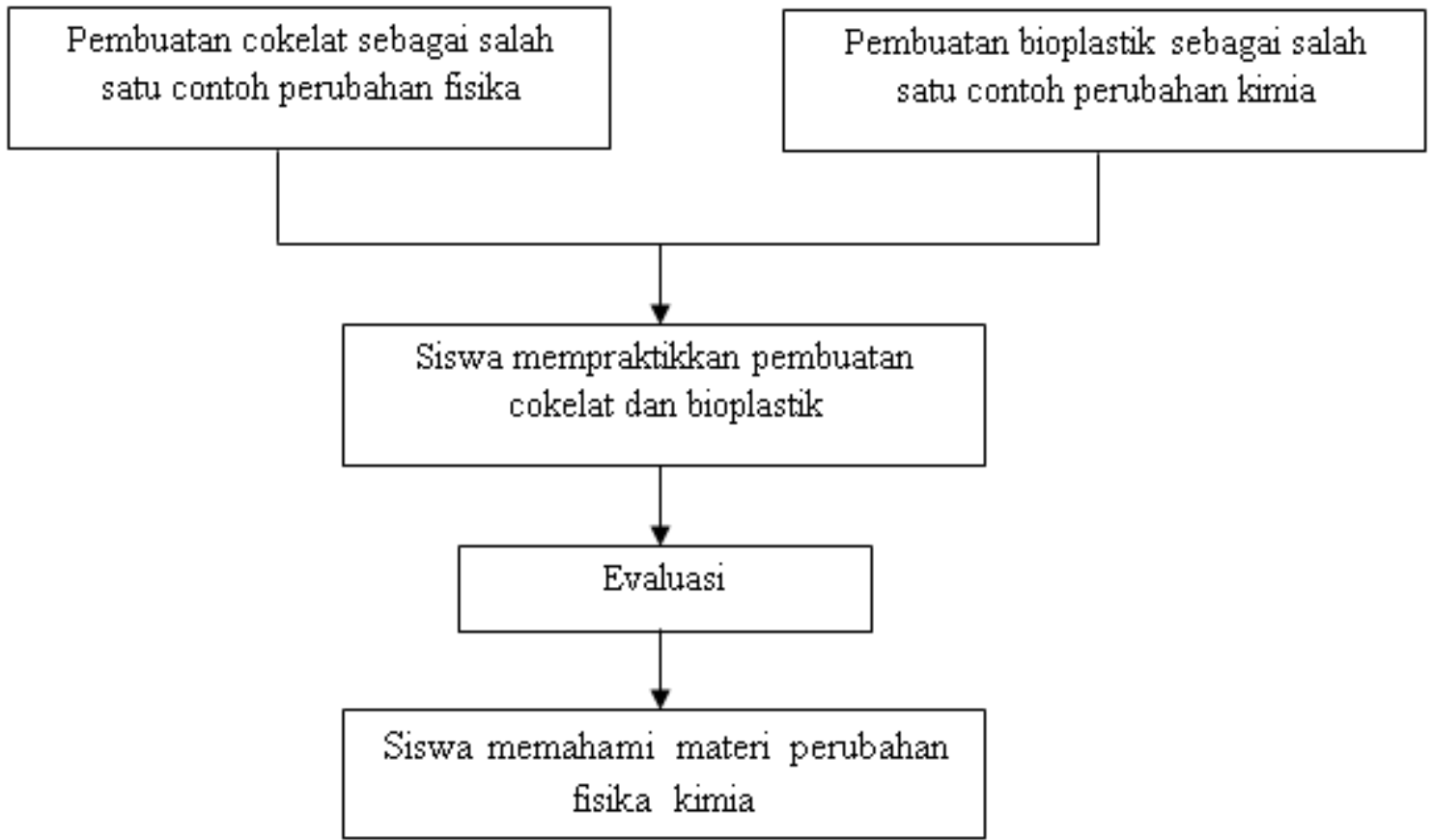

\section{HASIL DAN PEMBAHASAN}

Pembelajaran materi perubahan fisika kimia umumnya hanya berupa pencarian literatur atau memperlihatkan gambar maupun contoh dari benda yang mengalami perubahan fisika dan kimia. Pembelajaran yang hanya memperlihatkan hasil tanpa menunjukkan proses akan mengakibatkan siswa berpikir abstrak dan cenderung kurang memahami materi secara mendalam.

Mengajak siswa untuk melakukan kegiatan yang menunjukkan proses perubahan fisika kimia yang terjadi di dalamnya akan membuat siswa lebih memahami materi tersebut. Pembuatan cokelat merupakan materi untuk perubahan fisika dan bioplastik untuk perubahan kimia. Siswa dapat mengetahui secara langsung proses yang terjadi di dalamnya sehingga siswa dapat menarik kesimpulan tentang perbedaan perubahan fisika kimia dengan tepat.

Selain siswa dapat terlibat aktif, pembelajaran ini menyenangkan karena setelah cokelat selesai mereka buat, siswa dapat memakannya bersama-sama. Selain itu, pembuatan bioplastik merupakan langkah awal pembelajaran siswa untuk dapat mengatasi kerusakan lingkungan dengan menciptakan bioplastik yang ramah lingkungan, dapat terurai di alam, dan tidak menyumbangkan permasalahan lingkungan.

Hasil evaluasi pembuatan cokelat menunjukkan 8 siswa merasa sangat senang dan 18 siswa merasa senang dengan pembelajaran dengan metode tersebut. Alasan mereka bermacam-macam mulai dari seru, lucu, bisa mencoba hal yang baru, dan bisa makan cokelat. Untuk kesulitan yang mereka alami seperti panci atau cokelat yang gosong, panci yang bukan teflon, dan kurangnya bahan dapat mereka atasi dengan cara mengulangi kembali pembuatan cokelat, 
menggunakan panci stainless dan di bawahnya diberi air agar tidak terlalu panas, serta meminta bahan pada kelompok yang lain bagi kelompok yang kekurangan bahan.

Cokelat yang mereka hasilkan jumlahnya bervariasi mulai dari 2 hingga 40 buah cokelat menyesuaikan besarnya cetakan dan bahan yang mereka bawa. Untuk melatih jiwa kewirausahaan tergantung pada jumlah cokelat yang dihasilkan. Bagi kelompok yang menghasilkan sedikit cokelat, mereka cenderung tidak berminat untuk menjualnya karena lebih memilih dimakan sendiri karena rasanya enak.

Perubahan fisika yang terjadi pada pembuatan cokelat adalah ketika dipanaskan cokelat akan meleleh dan terjadi perubahan dari wujud padat ke cair, kemudian setelah cokelat dimasukkan ke dalam cetakan dan didinginkan dalam lemari es maka cokelat akan kembali membeku dan terjadi perubahan wujud dari cair menjadi padat. Pembuatan cokelat dapat membuktikan bahwa perubahan fisika tidak menghasilkan zat yang jenisnya baru dan dapat kembali ke wujud asal. Sebanyak 25 siswa mampu menjelaskan dan menyimpulkan proses perubahan fisika yang terjadi pada pembuatan cokelat, hanya 1 siswa yang belum dapat menjelaskan proses tersebut dengan baik.

Evaluasi pada pembuatan bioplastik menunjukkan seluruh siswa mampu menyebutkan bahan-bahan yang dipakai untuk pembuatan bioplastik sehingga diharapkan siswa dapat mengembangkan bioplastik di kemudian hari sehingga mampu menjadi problem solver untuk permasalahan lingkungan.

Dari bahan-bahan yang telah disediakan dan melalui proses pemanasan, siswa dapat mengetahui bahwa ciri-ciri perubahan kimia adalah terjadi reaksi kimia, menghasilkan zat yang jenisnya baru, serta hasilnya tidak dapat kembali ke bentuk semula. Seluruh siswa mampu menjelaskan dan menyimpulkan proses perubahan kimia yang terjadi pada pembuatan bioplastik dengan baik. Dompet, tas, bunga, kantong plastik, wadah ringan, dan baju merupakan ide siswa yang mereka wujudkan ketika diminta untuk membuat produk dari bioplastik. Tujuan dari pembuatan produk dari bioplastik adalah agar siswa mampu mengembangkan bakat, imajinasi, daya cipta, dan kreativitas mereka.

Alat penilaian tes adalah tes atau soal yang harus diselesaikan oleh siswa secara tertulis. Tes tertulis berbentuk pilihan ganda dan uraian. Soal bentuk pilihan ganda diberi skor 1 (satu) untuk setiap butir jawaban yang benar dan 0 (nol) untuk jawaban yang salah. Soal bentuk uraian diberi skor 4 untuk jawaban yang benar. Data hasil analisis pencapaian tes tertulis, dapat ditunjukkan hasilnya pada tabel 1 . 
Tabel 1. Hasil Analisis Pencapaian Tes Tertulis

\begin{tabular}{clcc}
\hline No & \multicolumn{1}{c}{ Aspek } & Angka Pencapaian & Teknik Pengukuran \\
\hline 1 & Rata-rata & 80,44 & Diukur melalui tes tertulis \\
2 & Ketuntasan & $70,37 \%$ & \\
3 & Nilai tertinggi & 100 & \\
4 & Nilai terendah & 36 & \\
& & & \\
\hline
\end{tabular}

Pembelajaran materi perubahan fisika kimia melalui pembuatan cokelat dan bioplastik dapat ditunjukkan dengan hasil sebagai berikut: total keseluruhan siswa adalah 27 siswa, ratarata kelas 80,44, ketuntasan siswa yang mencapai KKM 75 yaitu sebesar 70,37 \% atau sejumlah 19 siswa. Sedangkan nilai tertinggi yang mampu diraih siswa adalah nilai sempurna 100 dan nilai terendah mendapat nilai 36 .

\section{KESIMPULAN DAN SARAN}

Berdasarkan pembelajaran yang telah dilakukan dapat disimpulkan bahwa: pembuatan cokelat dan bioplastik efektif untuk pemahaman materi perubahan fisika kimia. Dari 26 siswa yang diuji, hanya 1 siswa yang kurang memahami materi pembelajaran. Berdasarkan hasil karya ilmiah dan simpulan di atas maka penulis menyarankan kepada rekan guru diharapkan dapat merancang metode pembelajaran lainnya yang dapat membantu pemahaman siswa dalam materi pelajaran, selain itu juga dalam rangka menciptakan pembelajaran yang aktif, kreatif, efektif, dan menyenangkan.

\section{DAFTAR PUSTAKA}

Aprilia, S. (2015). Penerapan Pembelajaran Experiental Learning untuk Meningkatkan Kualitas Pembelajaran IPA Kelas V Sekolah Dasar. Premiere Educandum, Volume 5, Nomor 1, Juni 2015, 20-33.

Istigfaroh, Z. (2014). Pelaksanaan Model Pembelajaran Experiental Learning di Pendidikan Dasar Sekolah Alam Anak Prima Yogyakarta. Artikel Jurnal.

Nurhasanah, S., Malik. A., Mulhayatiah, D. (2017). Penerapan Model Experiential Learning untuk Meningkatkan Keterampilan Berpikir Kritis Siswa. Jurnal Wahana Pendidikan Fisika. Vol. 2 No. 2: 58-62.

Triyono, M.B. (2017, Oktober). Tantangan Revolusi Industri ke 4 (i4.0) Bagi Pendidikan Vokasi. In Seminar Nasional Vokasi dan Teknologi. ISSN Cetak: 2541-2361.

Yahya, M. (2018). Era Industri 4.0: Tantangan dan Peluang Perkembangan Pendidikan Kejuruan Indonesia. Pidato Sidang Senat Terbuka Luar Biasa Senat Universitas Negeri Makasar. 